\title{
3-Phase 4-Wire Shunt Active Power Filter with Renewable Energy Interface
}

\author{
J. G. Pinto ${ }^{1}$, R. Pregitzer ${ }^{1}$, Luís F. C. Monteiro ${ }^{1}$, João L. Afonso ${ }^{1}$ \\ ${ }^{1}$ Department of Industrial Electronics \\ University of Minho \\ Campus de Azurém, 4800-058 Guimarães, Portugal \\ Phone:+351 253510190
}

E-mail: gpinto@dei.uminho.pt, rpregitzer@dei.uminho.pt, lmonteiro@dei.uminho.pt, jla@dei.uminho.pt

\begin{abstract}
This paper presents a three-phase four-wire Shunt Active Filter that compensates power quality problems and can also interface renewable energy sources with the electric grid. The inverter stage of the active filter is based in a two-level four-leg inverter and its control is based in the Theory of Instantaneous Reactive Power (p-q Theory). The filter is capable of compensating power factor, unbalance, and current harmonics. Additionally it can also make the interface between renewable energy sources and the electrical system, injecting balanced practically sinusoidal currents (with low THD).
\end{abstract}

\section{Key words}

Shunt Active Power Filter, Instantaneous Power Theory, Digital Signal Processing, Computer Simulations, Power Quality.

\section{Introduction}

The growing concern regarding global heating and climate change has stimulated the development of environment friendly energy generation technologies. In the near future, because of the Kyoto protocol and other international accords, the electrical grid will include a very large number of small producers that use renewable energy sources, like solar panels or wind generators, among other technologies.

One of the most common problems when connecting small renewable energy systems to the electric grid concerns the interface unit between the power sources and the grid, because it can inject harmonic components that may deteriorate the power quality.

This paper suggests a new method that consists in using a Shunt Active Filter [1] that is capable of simultaneously compensating problems like power factor, current imbalance and current harmonics, and also of injecting the energy generated by renewable energy power sources with a very low THD. Even when there is no energy available from the power source (when there is no sun or wind) the Shunt Active Filter can still operate, increasing the power quality of the electric grid. Applying a control strategy based on the Instantaneous Reactive Power Theory, it is very simple to inject reactive "energy" when necessary, or to inject the energy with unit power factor.

Fig. 1 illustrates the proposed system. A dc-dc converter can be used to adjust the value of the output voltage of the renewable energy sources to the voltage value of the dc-side capacitor of the Shunt Active Filter. The available energy is then managed by the controller of the active filter.

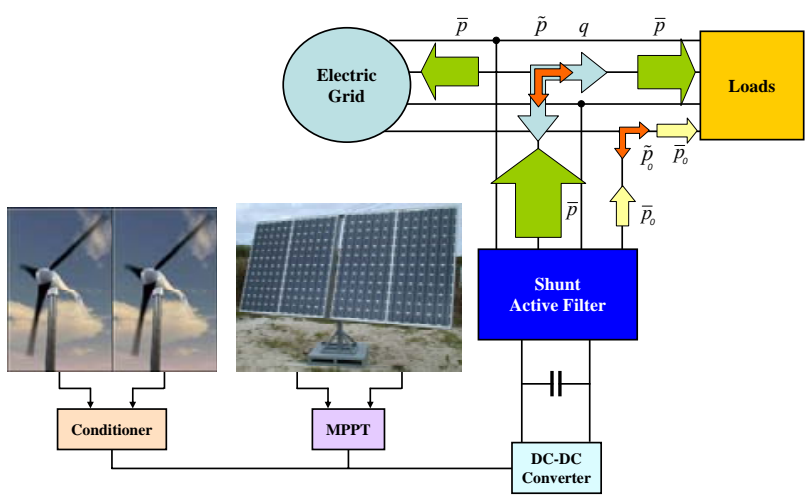

Fig. 1. Interface system and p-q theory power components

\section{The Instantaneous Reactive Power Theory}

The control strategy is based on the p-q theory introduced by Akagi et al. [2] and expanded to three-phase four-wire systems by Aredes et al. [3]. It applies an algebraic transformation (Clarke transform) of the three-phase system voltages and load currents in the $a-b-c$ coordinates to the $\alpha-\beta-0$ coordinates.

After the transformation, the $\mathrm{p}-\mathrm{q}$ theory components are achieved by the expressions (1-3), where $p$ is the instantaneous real power, $q$ is the instantaneous imaginary power (by definition) and $p_{0}$ is the instantaneous zero-sequence power.

$$
\begin{aligned}
& p=v_{\alpha} \cdot i_{\alpha}+v_{\beta} \cdot i_{\beta} \\
& q=v_{\beta} \cdot i_{\alpha}-v_{\alpha} \cdot i_{\beta}
\end{aligned}
$$




$$
p_{0}=v_{0} \cdot i_{0}
$$

Each one of the instantaneous power components can be separated into an average value and an oscillating value. The physical meaning of each of the instantaneous powers is:

- $\quad \bar{p}$ - average value of the instantaneous real power $p$. Corresponds to the energy per time unit transferred from the source to the load, in a balanced way through the 3 phases;

- $\quad \tilde{p}_{-}$Oscillating value of the instantaneous real power. It is the energy per time unity that is exchanged between the power source and the load, through the 3 phases;

- $q$ - The instantaneous imaginary power, q. Corresponds to the power that is exchanged between the phases of the load. This component does not imply any transference or exchange of energy between the power supply and the load, but is responsible for the existence of undesirable currents imply any transference or exchange of energy hotween the power source and the load;

- $\quad \bar{p}_{0}-$ Mean value of the instantaneous zero-sequence power. It corresponds to the energy per time unity that is transferred from the power source to the load through the zero-sequence components of voltage and current;

- $\quad \widetilde{p}_{0}$ - Oscillating value of the instantaneous zerosequence power. It means the energy per time unity that is exchanged between the power source and the load through the zero-sequence components of voltage and current.

In addition to the standard power components, two new ones were also used in order to consider the energy coming from the renewable energy sources: $p_{\text {res }}$ and $q_{\text {res }}$. The first one corresponds to the energy per time unit transferred from the renewable energy sources to the electric grid. As for $q_{\text {res }}$, it is used because according to the Portuguese Law, it is compulsory to inject capacitive reactive "energy" during certain periods of the day, and therefore this must be considered in the control system. There is also a component, $p_{\text {reg }}$, which is used to regulate the capacitor voltage when there is no energy available from the renewable power sources.

The power components that will be injected by the Shunt Active Filter, $p_{x}$ and $q_{x}$, include the undesired power quality effects to be compensated (harmonics, unbalance and reactive power) as well as the energy available in the renewable sources.

$$
\begin{aligned}
& p_{x}=p_{\text {res }}-p_{\text {reg }}+\tilde{p} \\
& q_{x}=\bar{q}_{r e s}+q
\end{aligned}
$$

Finally, it is possible to calculate the reference currents, in the $\alpha-\beta-0$ coordinates, by applying the expressions (6) and (7). The reference currents are then translated to the $a-b-c$ coordinates through the inverse Clarke transform.

$$
\begin{aligned}
{\left[\begin{array}{l}
i_{c \alpha} \\
i_{c \beta}
\end{array}\right] } & =\frac{1}{v_{\alpha}^{2}+v_{\beta}^{2}} \cdot\left[\begin{array}{cc}
v_{\alpha} & v_{\beta} \\
-v_{\beta} & v_{\alpha}
\end{array}\right] \cdot\left[\begin{array}{l}
p_{x} \\
q_{x}
\end{array}\right] \\
i_{c 0} & =i_{0}=\frac{1}{\sqrt{3}} \cdot\left(i_{a}+i_{b}+i_{c}\right)
\end{aligned}
$$

\section{Power Stage of the Shunt Active Filter}

The power stage of the Shunt Active Power Filter consists of a standard two-level Voltage Source Inverter with four legs, that uses IGBTs. The capacitor voltage can be kept constant by the renewable energy sources. If there is no energy available from these sources, the control algorithm changes and the energy required to maintain this voltage constant is drained from the electric grid. The inductors $(L)$ are used to connect the inverter to the electric grid. The controller requires the three system voltages $\left(v_{a}, v_{b}, v_{c}\right)$, the dc link voltage $\left(V_{d c}\right)$, the four load currents $\left(i_{L a}, i_{L b}, i_{L c}, i_{L n}\right)$, and the four inverter currents $\left(i_{f a}, i_{f b}, i_{f c}, i_{f n}\right)$. When the Shunt Active Power Filter is connected, the source currents $\left(i_{s a}, i_{s b}, i_{s c}\right)$, become balanced and sinusoidal, and the neutral source current $\left(i_{s n}\right)$ becomes practically zero.

The modulation technique used to drive the IGBTs is the Periodic Sampling, which is a very simple technique that establishes an upper frequency limit, but does not work with a fixed switching frequency [5].

The first results were obtained using a computer simulation tool (PSCAD), in order to validate the proposed control algorithm. A second phase consisted in implementing a laboratory prototype of the described Shunt Active Filter and testing the proposed control theory. In Fig. 2 it is possible to see the implemented prototype. It uses a Texas Instruments DSP, and the control system was implemented using only fixed-point calculations in order to enhance performance in terms of execution time. Hall-effect sensors were used to measure the voltages and currents. The inverter stage was implemented using 2 Mitsubishi IGBT modules.

Fig. 3 shows the block diagram of the Shunt Active Filter.

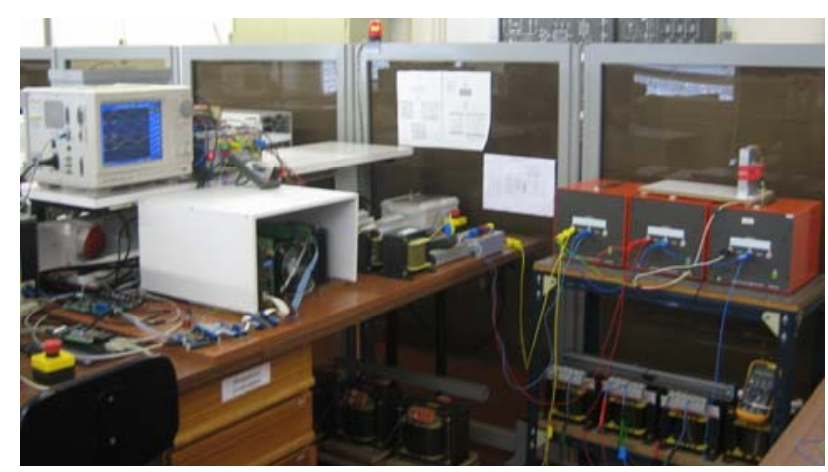

Fig. 2. Laboratory prototype of the Shunt Active Filter. 


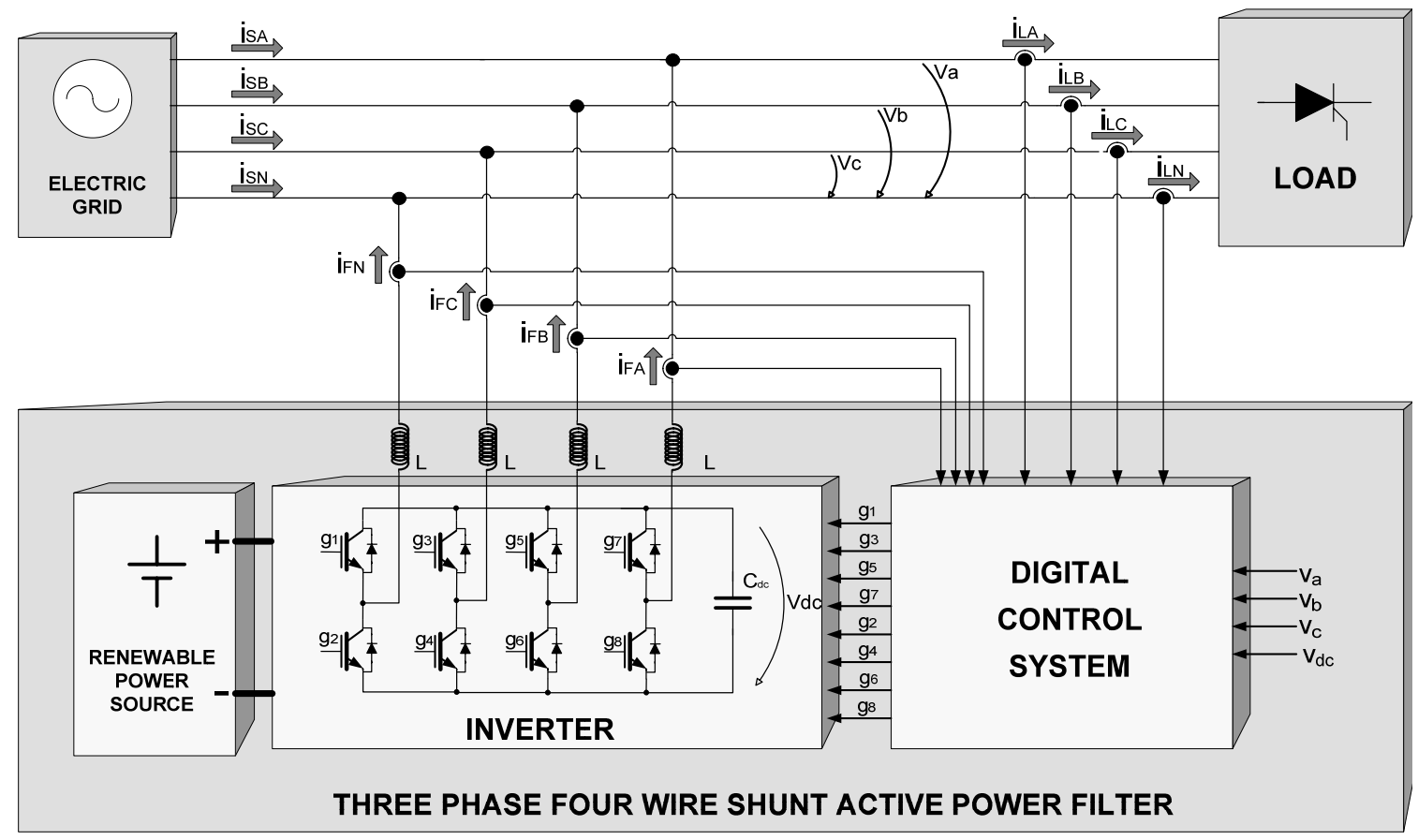

Fig. 3. Block diagram of the three-phase four wire Shunt Active Power Filter in the electric system.

\section{Simulation and Experimental Results}

Several tests were made to verify the performance of the Shunt Active Filter in various operating conditions. The simulation model is accurately modelled, and therefore the results are very similar to the ones measured in the laboratory prototype. Some of the techniques used to make an accurate simulation model are described in [4]. The obtained results are grouped and presented in the next three topics. In each topic is presented a short description of the testing system, followed by the obtained simulation and experimental results. All the test cases presented were performed in a $75 \mathrm{~V} / 50 \mathrm{~Hz}$ electric system.

\section{A. Active Power Filter injecting energy in the electric grid}

This case study is used to test the active filter performance injecting energy in the electric grid without compensating any loads. Fig. 4 shows the electrical system used to test the active filter.

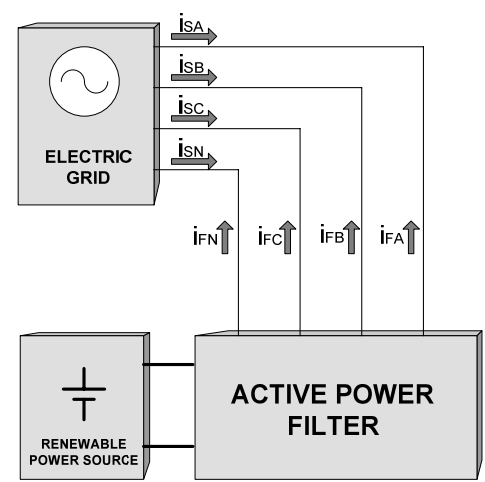

Fig. 4. Electrical system to test the Shunt Active Filter injecting energy in the electric grid
The simulation results, presented in Fig. 5 and the measured results, shown in Fig. 6 demonstrate that the Shunt Active Power Filter performs well under these conditions. The injected currents are balanced, sinusoidal and only active power is injected, however it is also possible to inject reactive power, if necessary [6]. The total injected three phase active power is of about $1100 \mathrm{~W}$.

In Fig. 6 the voltage scale is $50 \mathrm{~V} / \mathrm{div}$ and the current scale is $4 \mathrm{~A} /$ div.

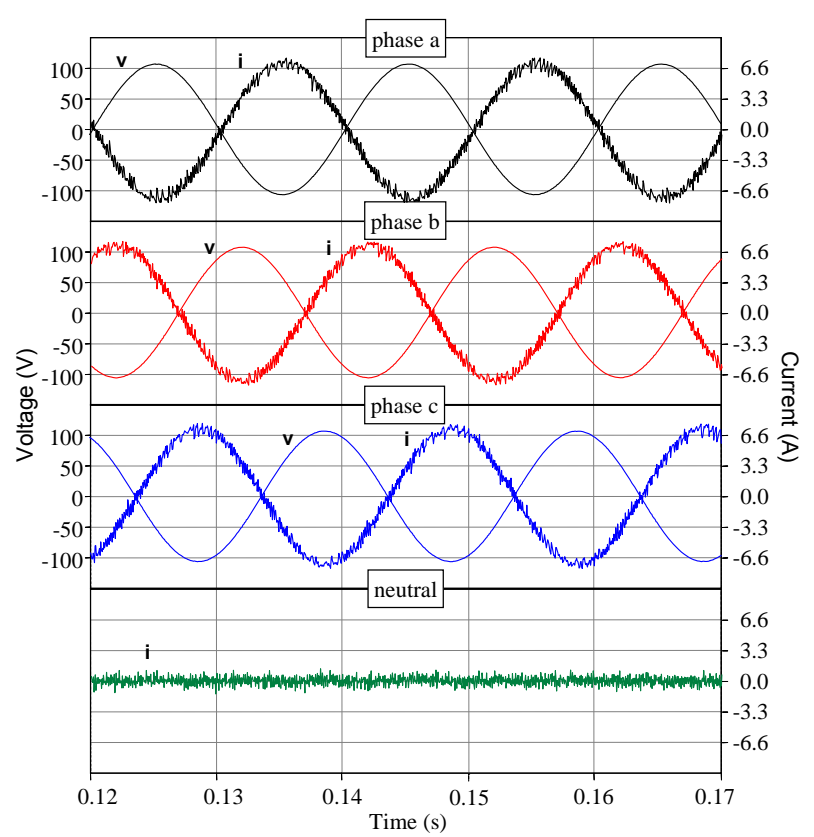

Fig. 5. Simulated system voltages and source currents 


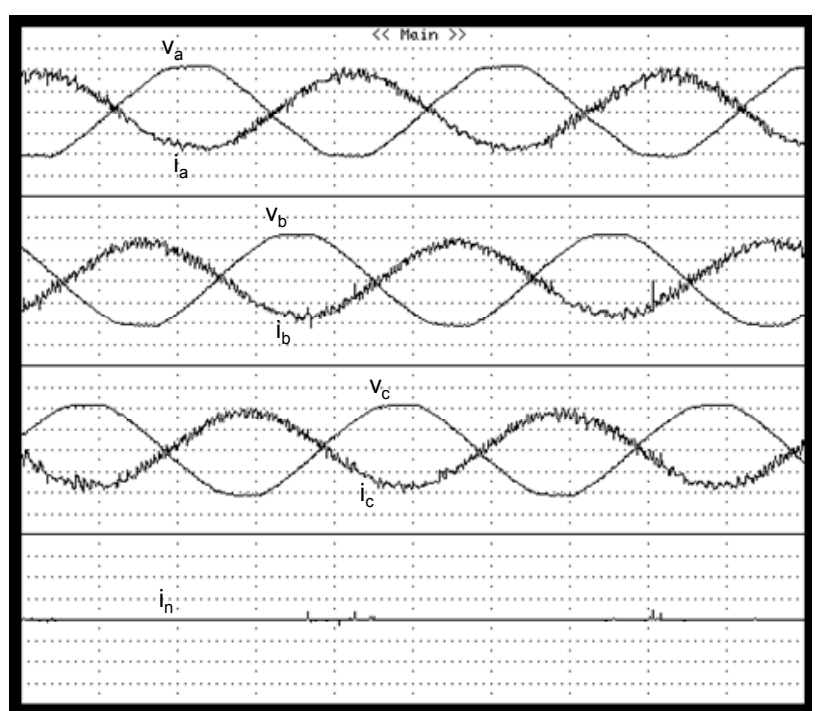

Fig. 6. Measured system voltages and source currents

B. Active Power Filter compensating harmonics, power factor, and injecting energy in the electric grid

This case study is used to test the active filter when it is simultaneously injecting energy and compensating a non linear load. Fig. 6 shows the electric system used to test the active filter. The load is composed by a three phase $200 \mathrm{mH}$ inductor and a three phase diode bridge rectifier with a $60 \Omega$ resistor in series with a $68 \mathrm{mH}$ inductor at the dc side.

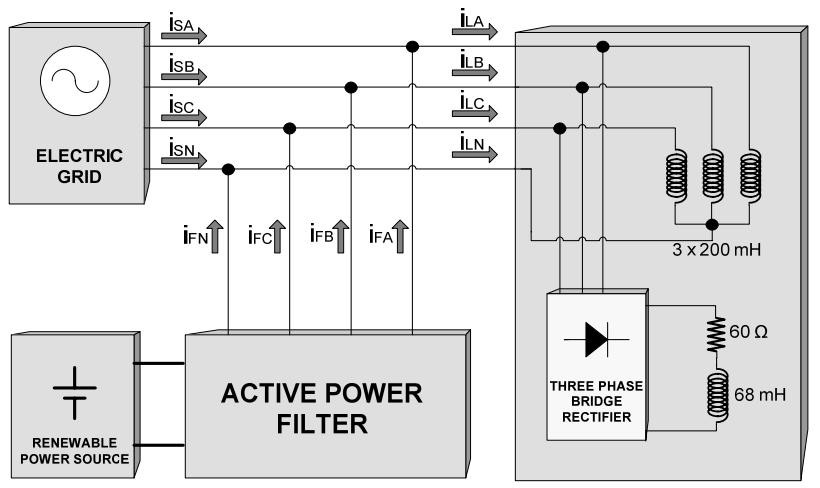

Fig. 7. Electrical system to test the Shunt Active Filter compensating harmonics, power factor and simultaneously injecting energy.

Fig. 8 illustrates the simulated system voltages and load currents, and Fig. 9 shows the simulated system voltages and source currents when the filter is in steady state, compensating the current harmonics, the power factor, and is at the same time injecting active power. The phase of the source currents are inverted relatively to the voltages because the injected energy is sufficient to feed the non linear load and to inject energy in the electric grid. These currents are sinusoidal and present a very high power factor. The high frequency noise that can be observed is due to the switching of the IGBTs, and the current spikes are caused by the delays in the controller, that is not able to compensate the fast variations of the load currents. This high frequency noise and the compensation delay are also visible in the measured source currents presented in Fig. 11.

Fig. 10 shows the measured load currents and Fig. 11 shows the source currents after the compensation of the Shunt Active Filter. All figures also present the system voltages. It is possible to observe once again that the simulated and experimental results are very similar. The voltage scale is $50 \mathrm{~V} / \mathrm{div}$ and the current scale is $2 \mathrm{~A} / \mathrm{div}$ for figures 10 and 11 .

The total active power consumed by the loads is of about $530 \mathrm{~W}$ and the active filter is supplying a total active power of $1300 \mathrm{~W}$, therefore the power injected to the source is $770 \mathrm{~W}$. The active filter also supplies all the reactive power required by the loads.

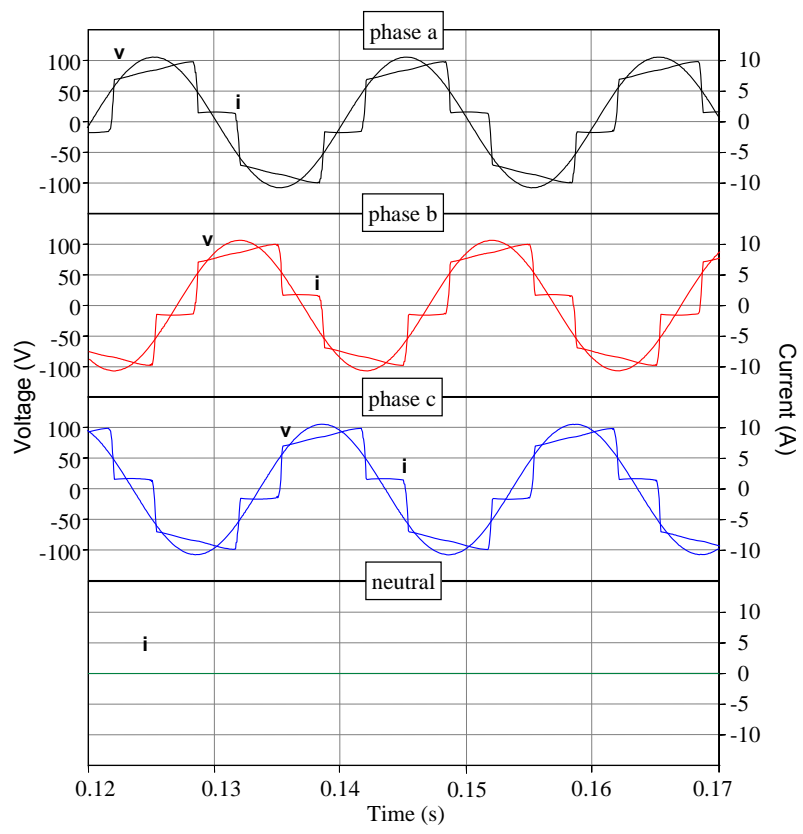

Fig. 8. Simulated system voltages and load currents

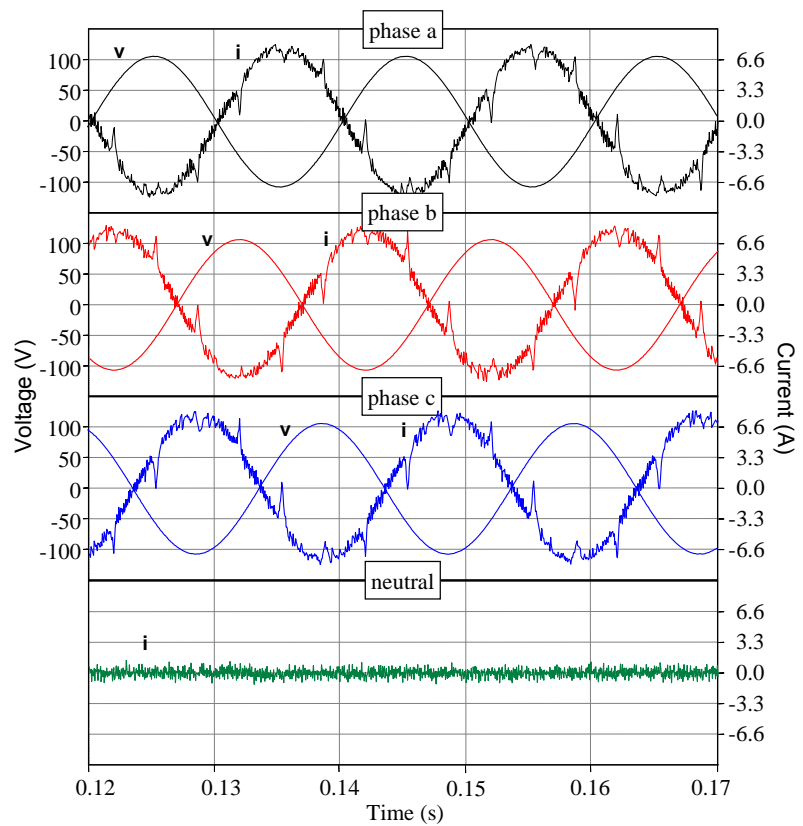

Fig. 9. Simulated system voltages and source currents 


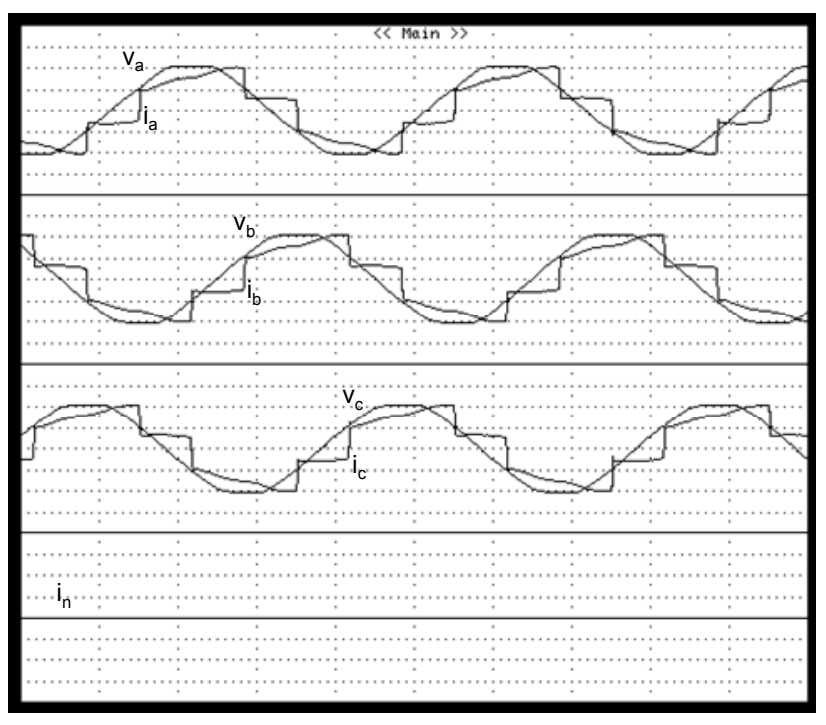

Fig. 10. Measured system voltages and load currents

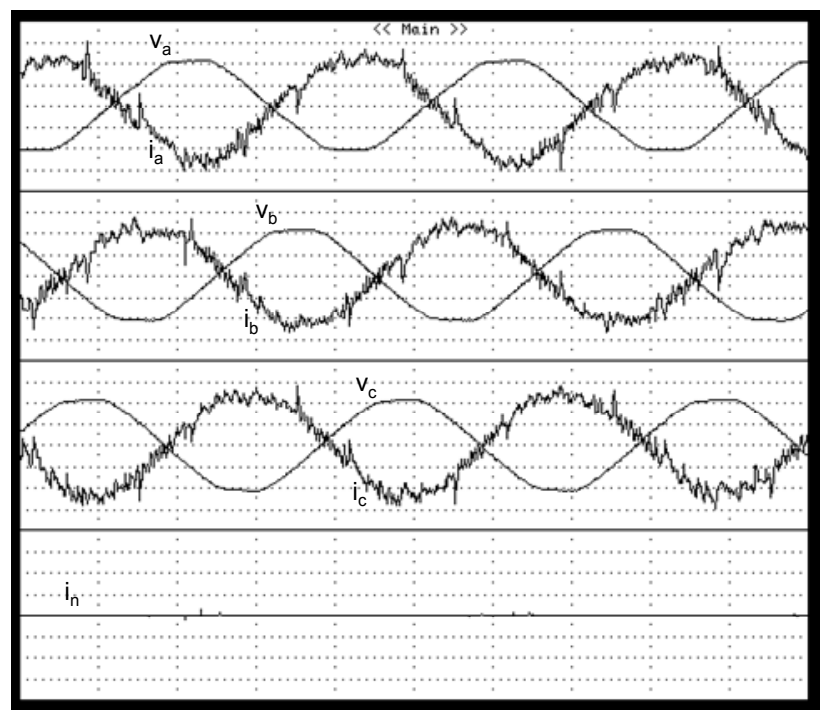

Fig. 11. Measured system voltages and source currents

C. Active Power Filter compensating harmonics, power factor, unbalance and injecting energy in the electric grid

This case study is used to test the active filter while simultaneously injecting energy and compensating a non linear and unbalanced load. Fig. 12 shows the electrical system used to test the active filter. The load is composed by two $200 \mathrm{mH}$ inductors (applied between phases $a$ and $b$ ) and by a single-phase diode bridge rectifier with a $20 \Omega$ resistor in series with a $68 \mathrm{mH}$ inductor at the dc side. The bridge rectifier is connected between the phase $a$ and the neutral.

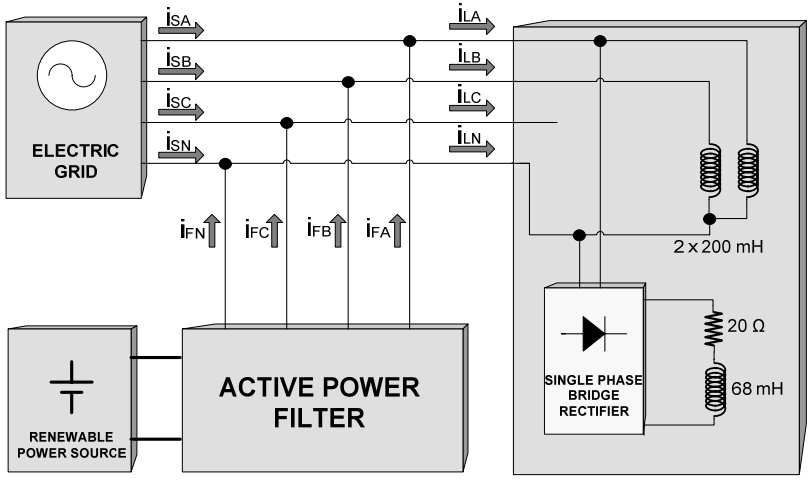

Fig. 12. Electrical system to test the Shunt Active Filter compensating harmonics, power factor, unbalance and simultaneously injecting energy.

Figures 13 and 14 present the simulated load currents and the simulated source currents, respectively. The correspondent measured currents are shown in Figures 15 and 16. Comparing with the previous case, it is possible to see that the transients caused by the delays of the control system are not visible, because the single phase non linear load has a smaller di/dt.

The voltage scale for figures 15 and 16 is $50 \mathrm{~V} / \mathrm{div}$, and the current scale for Fig. 15 is $4 \mathrm{~A} /$ div and $2 \mathrm{~A} / \mathrm{div}$ for Fig. 16.

The total active power consumed by the loads is of about $220 \mathrm{~W}$ and the active filter is supplying a total active power of $1400 \mathrm{~W}$ therefore the power injected to the source is $1180 \mathrm{~W}$. The active filter also supplies all the reactive power required by the loads, and compensates the neutral current.

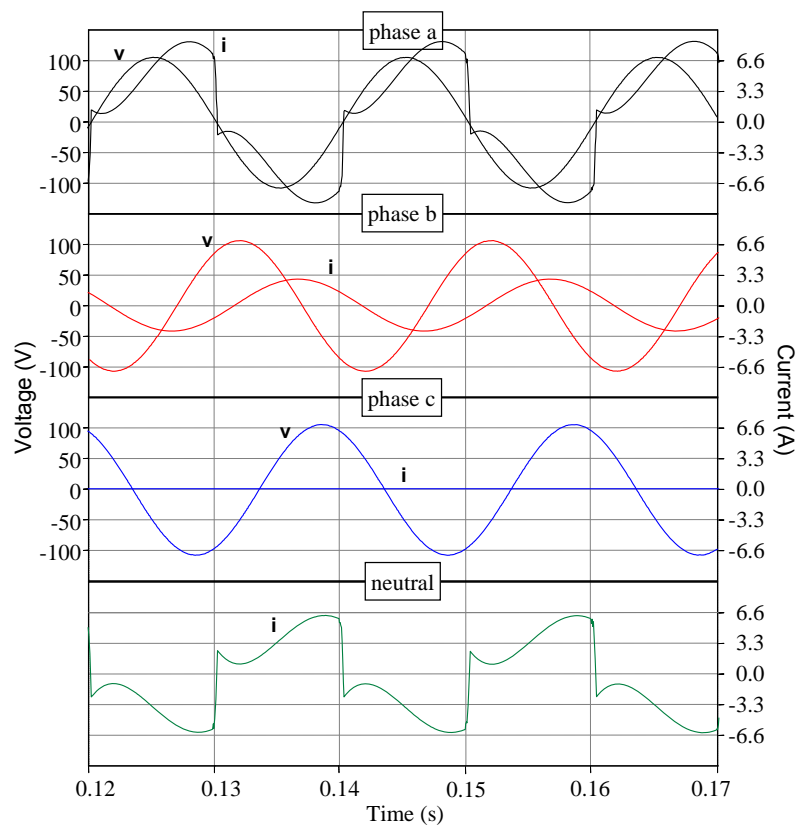

Fig. 13. Simulated system voltages and load currents 


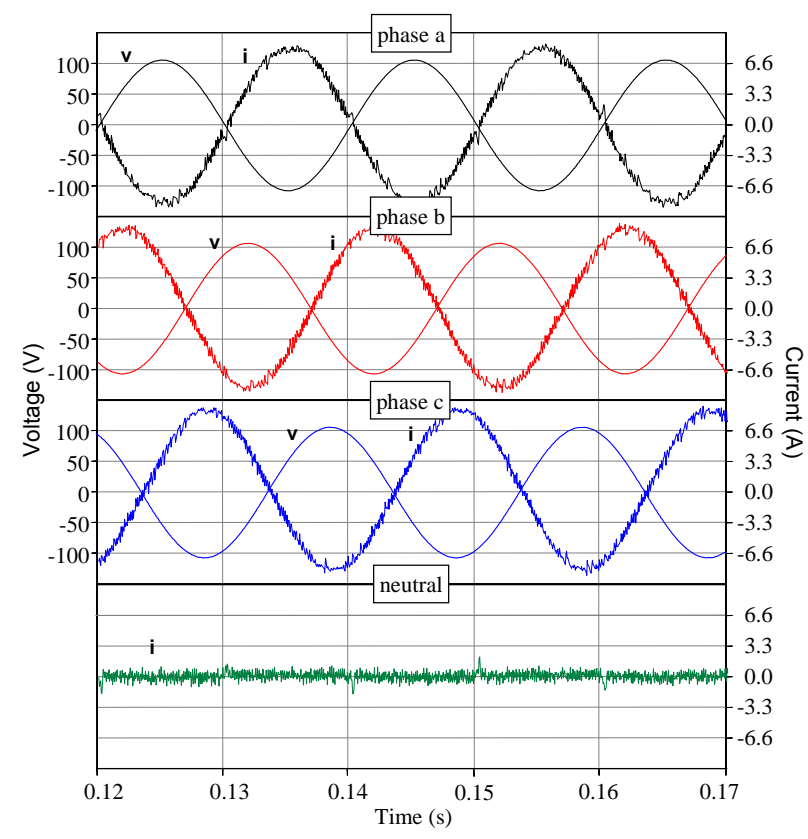

Fig. 14. Simulated system voltages and source currents

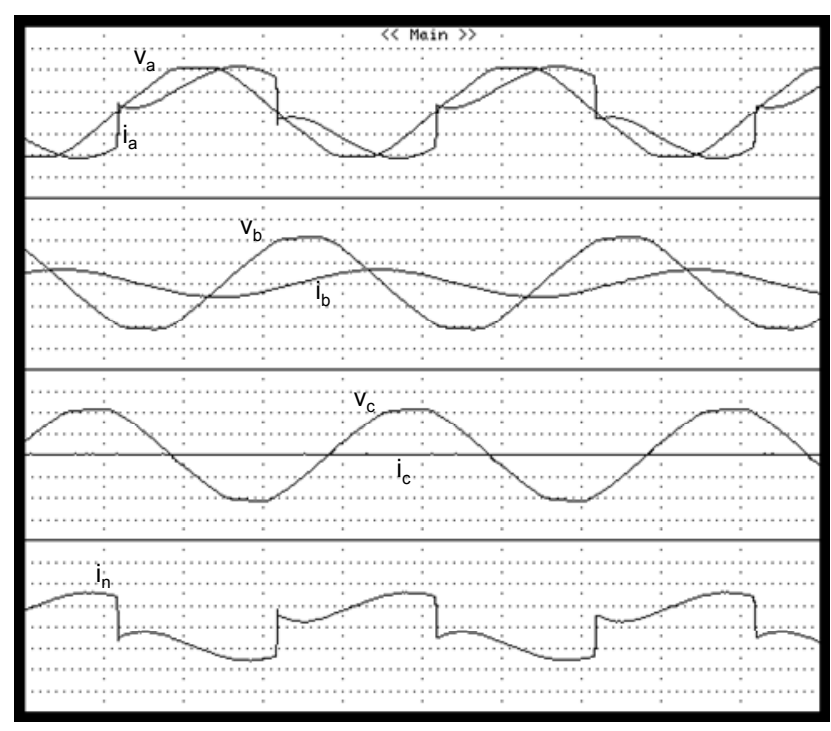

Fig. 15. Measured system voltages and load currents

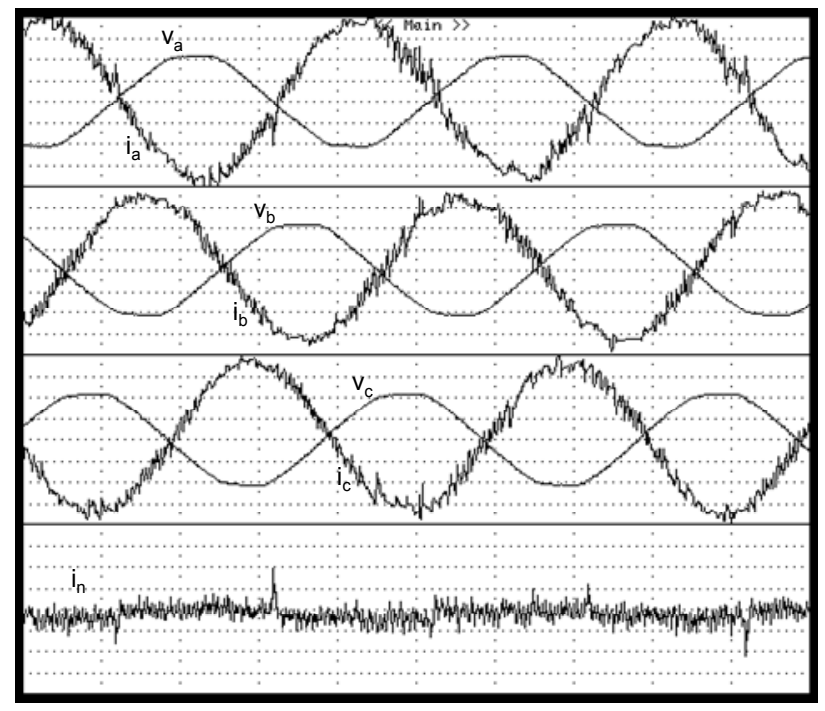

Fig. 16. Measured system voltages and source currents

\section{Conclusions and Future Work}

This paper suggests the use of a Shunt Active Filter as an interface between renewable energy sources and the electric grid. Simulation and implementation results show the feasibility of the proposed control strategy. The Shunt Active Filter has the capability of injecting sinusoidal currents with low THD, and it can also compensate problems like current harmonics, unbalance and power factor.

The authors are currently researching other switching techniques for the inverter of the Shunt Active Filter, in order to improve the performance of the power stage by reducing the noise injected in the electric grid.

\section{Acknowledgement}

This work was supported by the FCT (Fundação para a Ciência e Tecnologia), project funding POCTI/ESE/41170/2001 and POCTI/ESE/48242/2002. The authors are also grateful to PRIME (Programa de Incentivos à Modernização da Economia) for funding the Project SINUS.

The author Luís F. C. Monteiro is grateful to Alban program for supporting his education project at the University of Minho.

\section{References}

[1] João Afonso, Maurício Aredes, Edson Watanabe, Júlio Martins, "Shunt Active Filter for Power Quality Improvement”, International Conference UIE 2000 Electricity for a Sustainable Urban Development, Lisboa, Portugal, 1-4 November 2000, pp. 683- 691.

[2] H. Akagi, Y. Kanazawa, A. Nabae, "Generalized Theory of the Instantaneous Reactive Power in ThreePhase Circuits”, IPEC'83 - Int. Power Electronics Conf., Tokyo, Japan, 1983, pp. 1375-1386.

[3] M. Aredes; E. H. Watanabe; "New Control Algorithms for Series and Shunt Three-Phase Four-Wire Active Power Filters"; IEEE Transactions on Power Delivery, vol. 10, no. 3, Jul. 1995; pp.: 1649 - 1656.

[4] R. Pregitzer, J.C. Costa, Júlio S. Martins, J. L . Afonso, "Simulation and Implementation Results of a 3 Phase 4 Wire Shunt Active Power Filter", CDROM Proceedings of the ICHQP 2006 - International Conference on Harmonics and Quality of Power, Cascais, Portugal, 1-5 October 2006.

[5] S. Buso; L. Malesani; P. Mattavelli; Comparison of Current Control Techniques for Active Filter Applications; IEEE Transactions on Industrial Electronics, vol. 45, Issue 5, Oct. 1998; Page(s):722-729.

[6] Ricardo Pregitzer, José C. Costa, Júlio S. Martins, João L. Afonso, "Filtro Activo Paralelo como Interface entre Fontes de Energia Renovável e a Rede Eléctrica”, ENER'06 - Conferência sobre Energias Renováveis, Segurança e Integridade do Sistema Eléctrico, Figueira da Foz, Portugal, 28-30 de Setembro de 2006. 